\title{
MEDICAL PROFESSION : CHALLENGES IN NEPAL
}

\author{
Sulav Sapkota
}

Assistant professor

Department of Medical Oncology, Birat Medical College Teaching Hospital, Nepal

Email: dr.sulavsapkota@yahoo.com

https://orcid.org/0000-0003-4894-6455

\begin{tabular}{c} 
Citation \\
Sulav Sapkota, Medical Profession : Challenges in Nepal. \\
\hline
\end{tabular}

KEYWORDS: Medical ; Challenges; Nepal

DOI: https://doi.org/10.3126/bjhs.v6i3.43193

Nepal is a beautiful landlocked country mainly situated in the Himalayas, with the estimated population of about twentynine million. Health care services in Nepal is provided by both public and private sectors. The doctor to population ratio in Nepal is 1: $1724 .{ }^{1}$ According to statistics available in Nepal Medical Council register as on 31st December 2020, total of 28477 MBBS and BDS doctors and 8315 specialists have been registered. ${ }^{2}$

The Royal college of Physicians describe medicine as "a vocation in which a doctor's knowledge, clinical skill, and judgment are put in the service of protecting and restoring human well-being. This purpose is realised through a partnership between patient and doctor, one based on mutual respect, individual responsibility and appropriate accountability." ${ }^{3}$

It was in the year 2007, Nepal's Interim Constitution addressed health as a basic fundamental right where all the citizens have the right to access basic health services free of cost. ${ }^{4}$ Despite this, approximately forty percent of Nepalese do not have access to healthcare facilities within a 30 -minute radius. ${ }^{4}$

Amongst the healthcare providers in Nepal, private sector has grown at a faster pace covering mostly the central region of Nepal, which is the most developed region while the rural and the hilly areas are still deprived of the basic services and are mostly served by the public health care providers. Poverty, illiteracy, lack of health care providers, basic medicines ,full insurance coverage and lack of opportunities are all the hurdles medical professionals need to go through in public healthcare settings.

\section{REFERENCES}

1. Pathiyil Ravi Shankar.Brain drain and practice locations of Nepalese medical students. Janaki Medical College Journal of Medical Sciences (2017) Vol. 5(2): 1-4. DOI: http://dx.doi.org/10.3126/ jmcjms. v5i2.19010

2. https://nmc.org.np
Medical profession is a demanding profession that requires a lot of dedication, hard work and commitment. Recently, the general population is becoming more educated and demanding towards better health care along with the accountability in urban areas. We as frontiers, are facing increased public expectations, changing disease pattern like COVID-19, workplace violence, low salary scale, lack of opportunities, employment problem and mental stress. Nowadays in view the aforesaid issues, a larger number of Nepalese medical graduates are opting to migrate to developed nations in search of a better, secured working environment.

Many a times, lack of public awareness and poor rules and regulations towards health professionals has been a threat for workplace violence. While comparing the International standards, medical professionals in Nepal are very low paid despite their hard and strenuous duties. Nepal being a low resource country, has lack of opportunities resulting in more of unemployment as well as migration of the professionals for better life. Last but not the least is the problem of burnout among care givers due to increase in mental stress of medical professional due to lack of job satisfaction, financial burden, lack of family time and unsuccessful relationship. Very young, energetic medical professionals have succumbed due to mental stress which is a huge loss to our society and our country.

Concerned authorities and policy makers need to be vigilant and play an active role in tackling these issues and create a healthy, secured and peaceful environment for all medical profession to provide long lasting sustainable health care service to Nepal.
3. Royal College of Physicians . Doctors in society: medical professionalism in a changing world. London: Royal College of Physicians; 2005. Available from: https://cdn.shopify.com/s/files /1/0924/4392/files/ doctors_in_society_reportweb.pdf?15745311214883953343. Last accessed March 2016. [PubMed] [Google Scholar]

4. Mishra, S. R., Khanal, P., Karki, D. K., Kallestrup, P., \& Enemark, U. (2015). National health insurance policy in Nepal: challenges for implementation. Global health action, 8, 28763. https://doi.org/10.3402/gha.v8.28763 